Case Report

\title{
A Spontaneous Epithelial-Myoepithelial Carcinoma of the Submandibular Gland in a Sprague-Dawley Rat
}

\author{
Yinghua $\mathrm{Li}^{1 *}$, Hak-Soo Kim ${ }^{1}$, Min-Soo Kang ${ }^{1}$, Seo-Ho Shin ${ }^{1}$, Kyo-Hwan Koo ${ }^{1}$, Chul-Min Kim ${ }^{1}$, \\ Kap-Ho Kim ${ }^{1}$, Charles Peck ${ }^{1}$, Han-Ik Bae ${ }^{2}$, Ji Yun Jeong ${ }^{2}$, Jin Seok Kang ${ }^{3}$, and Boo-Hyon \\ Kang $^{1 *}$ \\ ${ }^{1}$ Department of Pathology, Chemon Co., Ltd., 240 Nampyeongro, Yangji-Myeon, Cheoin-Gu, Yongin-Si, Gyeonggi-Do 449-826, \\ Republic of Korea \\ ${ }^{2}$ Department of Pathology, Kyungpook National University Medical Center, 474 Hakjeongdong, Buk-gu, Daegu 702-210, Republic of \\ Korea \\ ${ }^{3}$ Department of Biomedical Laboratory Science, Namseoul University, Cheonan, Chungcheongnam-do 331-707, Republic of Korea
}

\begin{abstract}
The present report describes a rare case of spontaneous tumor of the salivary gland in a male Sprague-Dawley rat. The clinically confirmed mass rapidly developed in the cervical region between 19 and 21 weeks of age, and the animal was subsequently euthanized. At necropsy, a well-circumscribed nodule approximately $7 \times 6 \mathrm{~cm}$ in diameter was found at the site of the salivary gland. The cut surface of the nodule was lobulated and soft and had a pinkish tan fish-flesh appearance. One large cyst (approximately $3 \times 2$ $\mathrm{cm}$ in size) containing reddish fluid was also present in the nodule. Histopathologically, the tumor, with a partially lobulated structure, was surrounded by a thin fibrous capsule. The majority of tumor cells formed a diffuse solid sheet structure that mainly consisted of small ovoid or spindle-shaped cells. In the tumor periphery, some cells were arranged in nest-like structures. Small duct-like structures lined with a monolayer of cuboidal epithelial cells resembling an intercalated duct or large polygonal clear cells with a myoepithelial component were also observed. Mitotic figures and necrotic foci were frequently observed in solid areas. Immunohistochemically, the tumor cells were positive for cytokeratin, epithelial membrane antigen, vimentin, p63, $\alpha$-smooth muscle actin and calponin. The cells were negative for calcitonin, synaptophysin and chromogranin A. On the basis of these findings, the tumor was diagnosed as an epithelial-myoepithelial carcinoma originating from the luminal epithelial cells and myoepithelial cells in the submandibular gland. (DOI: 10.1293/tox.26.67; J Toxicol Pathol 2013; 26: 67-72)
\end{abstract}

Key words: epithelial-myoepithelial carcinoma, immunohistochemical features, Sprague-Dawley rat, submandibular gland

Spontaneous tumors of the salivary glands in rats are very rare ${ }^{1,2}$, and most of them are diagnosed as adenomas or adenocarcinomas originating from acinar cells or a ductal epithelium ${ }^{3}$. Several detailed reports have analyzed salivary gland tumors in rats, epithelial neoplasms in Wistar rats ${ }^{4,5}$, adenocarcinomas in a rnu/rnu nude rats ${ }^{6}$, pleomorphic adenomas and poorly differentiated carcinomas in SpragueDawley (SD) rats $^{7-9}$ and papillary cystadenocarcinomas in Fischer 344 rats $^{10}$. However, only a few cases of epithelialmyoepithelial carcinoma (EMC), which is morphologically characterized by the proliferation of tumor cells consisting of epithelial and myoepithelial components, have been reported in humans ${ }^{11-13}$. In comparison with humans, the histogenetic classification of salivary gland tumors in rodents

Received: 25 October 2012, Accepted: 3 December 2012

*Corresponding authors: Y Li (e-mail: 1-iyinghua@hanmail.net ) and B-H Kang (e-mail: bkang51@chemon.co.kr)

(C)2013 The Japanese Society of Toxicologic Pathology

This is an open-access article distributed under the terms of the Creative Commons Attribution Non-Commercial No Derivatives (by-ncnd) License $<$ http://creativecommons.org/licenses/by-nc-nd/3.0/> . is very simple ${ }^{14}$. To date, the term EMC has not been used for the classification of a rodent salivary gland tumor. This report describes detailed morphological and immunohistochemical (IHC) characteristics of a rodent EMC.

The animal was a male specific pathogen-free (SPF) SD rat (Hsd: Sprague Dawley ${ }^{\circledR} \mathrm{SD}^{\circledR}$ ) purchased from Koatech Inc., Republic of Korea. It was used as a vehicle control animal in a 13-week repeated-dose toxicity study and was submitted for sacrifice at the end of the study. The animal was housed in a solid bottom polycarbonate cage under routine controlled conditions (temperature, $23 \pm 3^{\circ} \mathrm{C}$; humidity, $55 \% \pm 15 \%$; lighting, 12 hours) and had free access to Teklad-certified, irradiated, global $18 \%$ protein rodent diet 2918C (Harlan Laboratories, Inc., USA) and sterilized tap water. At the end of the study, the animal was euthanized by exsanguination via the abdominal artery under isoflurane (Ifran liquid, Hana Pharm. Co., Ltd., Republic of Korea) anesthesia. The procedure for animal care was approved by the Institutional Animal Care and Use of Committees (IACUC) of Chemon Co., Ltd. based on the Animal Protection Act.

The mass was clinically confirmed to have rapidly developed in the cervical region from 19 weeks of age until 21 
weeks of age, when the animal was terminally sacrificed. At necropsy, a well-circumscribed nodule approximately $7 \times 6$ $\mathrm{cm}$ in diameter was found in the cervical region, in which normal submandibular, sublingual and parotid glands were not identified. The cut surface of the nodule was lobulated and soft and had a pinkish tan fish-flesh appearance. One large cyst (approximately $3 \times 2 \mathrm{~cm}$ in size) containing reddish fluid was also present in the nodule (Fig. 1). However, the animal showed no abnormalities with regard to body weight, hematology or blood chemistry. The mass and other organs (including submandibular gland, sublingual gland, parotid gland and submandibular lymph node) were fixed in $10 \%$ neutral-buffered formalin, embedded in paraffin, cut into 4- $\mu \mathrm{m}$ thick sections, stained with hematoxylin and eosin (H\&E) and examined microscopically. Additionally, IHC studies were performed on the tumor sections using a biotin-avidin peroxidase complex method and an automated immunostainer (BenchMark ${ }^{\circledR}$; Ventana Medical Systems, Inc., Tucson, AZ, USA). The antibodies used in this study are described in Table 1. An indirect biotin-streptavidin system (iView DAB Detection Kit; Ventana Medical Systems, Inc., Tucson, AZ, USA) was used as the secondary antibody. The tumor sections were counterstained with hematoxylin (Ventana Medical Systems, Inc., Tucson, AZ, USA) and then treated with Bluing Reagent (Ventana Medical Systems, Inc., Tucson, AZ, USA). The IHC staining was scored semiquantitatively as negative (-), positive for a limited number of cells $(+)$ and intensely positive for numerous cells $(++)$ according to the proportion of immunoreactive cells and the intensity of reactivity.

Microscopically, the tumor had a thin fibrous capsule, it compressed the surrounding tissue, and it had lobules separated by delicate connective tissue septa (Fig. 2A). Small nests of tumor cells were seen outside the capsule in some areas (Fig. 2B), and the tumor and residual submandibular gland were surrounded by a fibrous capsule (Fig. 2C). The

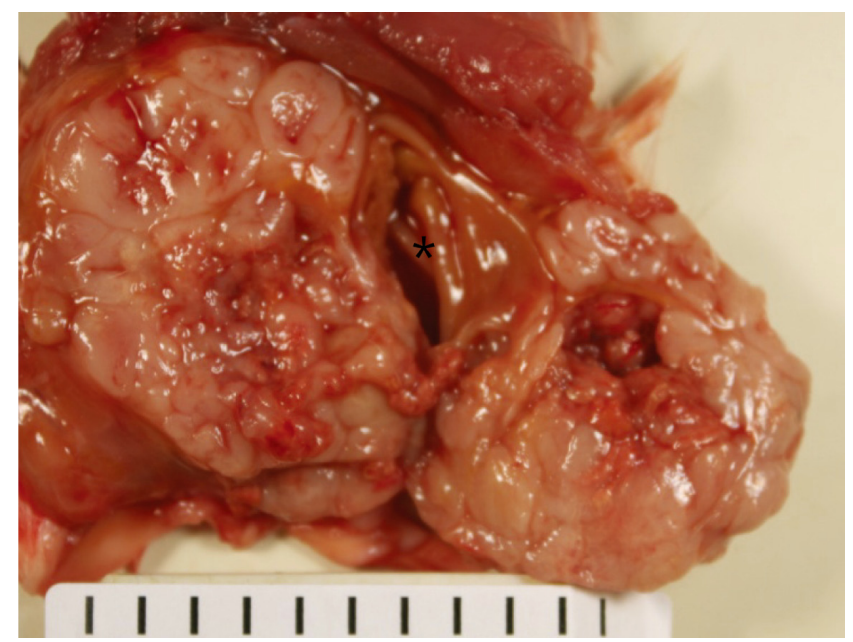

Fig. 1. Gross appearance of the tumor in the cervical region. The tumor is well circumscribed and lobulated and soft and had a pinkish tan fish-flesh appearance on the cut surface. One large cyst is present in the nodule (asterisk). 1 scale $=1 \mathrm{~cm}$. majority of the tumor cells formed a diffuse solid sheet structure that mainly consisted of small ovoid or spindle-shaped cells, with a pale oval nucleus containing a few prominent nucleoli (Fig. 2C). Along the tumor periphery, some tumor cells were arranged as nest-like structures. In some areas, small duct-like structures lined with a monolayer of cuboidal epithelial cells (Fig. 2D) resembling an intercalated duct or large polygonal clear cells with a myoepithelial component were observed (Fig. 2E) ${ }^{12}$. This characteristic myoepithelial component has been previously described in a human salivary gland tumor ${ }^{13}$. Mitotic figures were frequently observed throughout the tumor, suggesting that it grew rapidly. Necrotic foci were observed in solid areas (Fig. 2F). Cell debris and slight infiltration of neutrophils were present throughout the tumor (Fig. 2D). Slight infiltration of lymphocytes was seen in the thin connective tissue (Fig. 2B). Cribriform patterns, keratinization and arrangement of palisading cells were not found in the tumor. Microscopic examination revealed that there were no significant changes in other organs, especially in the submandibular lymph nodes, sublingual and parotid glands.

The results of IHC analysis for the tumor and normal part of the submandibular gland are summarized in Table 2. In the normal tissue of the salivary gland, the membranes and cytoplasm of ductal luminal epithelial cells showed a positive reaction for cytokeratin (CK AE1/AE3) (Fig. 3A), and the cytoplasm was also positive for epithelial membrane antigen (EMA). The myoepithelial cells just beneath the luminal epithelial cells showed a positive reaction for calponin, $\alpha$-smooth muscle actin ( $\alpha$ SMA) and vimentin in the cytoplasm and for p63 in the nuclei.

The duct-like structure of the epithelial component and the oval or spindle-shaped cells in the tumor showed a diffuse positive reaction for CK AE1/AE3 (Fig. 3A) in the membrane and cytoplasm and for EMA (Fig. 3B) in the cytoplasm. The large polygonal clear cells of the myoepithelial component and the oval or spindle-shaped cells in the tumor showed a positive reaction for vimentin (Fig. 3C), calponin and $\alpha$ SMA in the cytoplasm and for p63 (Fig. 3D) in the nuclei. However, the tumor cells were negative for calcitonin, synaptophysin and chromogranin A.

Table 1. Antibodies Used in IHC Staining of the Tumor and the Normal Part of the Salivary Gland

\begin{tabular}{lll}
\hline Marker & Source & Dilution \\
\hline CK AE1/AE3 & mAb (DAKO) mouse & $1: 200$ \\
EMA & mAb (DAKO) mouse & $1: 200$ \\
aSMA & mAb (DAKO) mouse & None (prediluted) \\
Vimentin & mAb (Signet) mouse & None (prediluted) \\
p63 & mAb (Ventana) mouse & None (prediluted) \\
Calponin & mAb (DAKO) mouse & $1: 100$ \\
Calcitonin & pAb (DAKO) rabbit & $1: 100$ \\
Synaptophysin & mAb (Ventana) rabbit & None (prediluted) \\
Chromogranin A & pAb (ABCAM) rabbit & $1: 100$ \\
\hline
\end{tabular}

CK AE1/AE3, cytokeratin AE1/AE3; EMA, epithelial membrane antigen; $\alpha$ SMA, $\alpha$-smooth muscle actin; pAb, polyclonal antibody; $\mathrm{mAb}$, monoclonal antibody. 

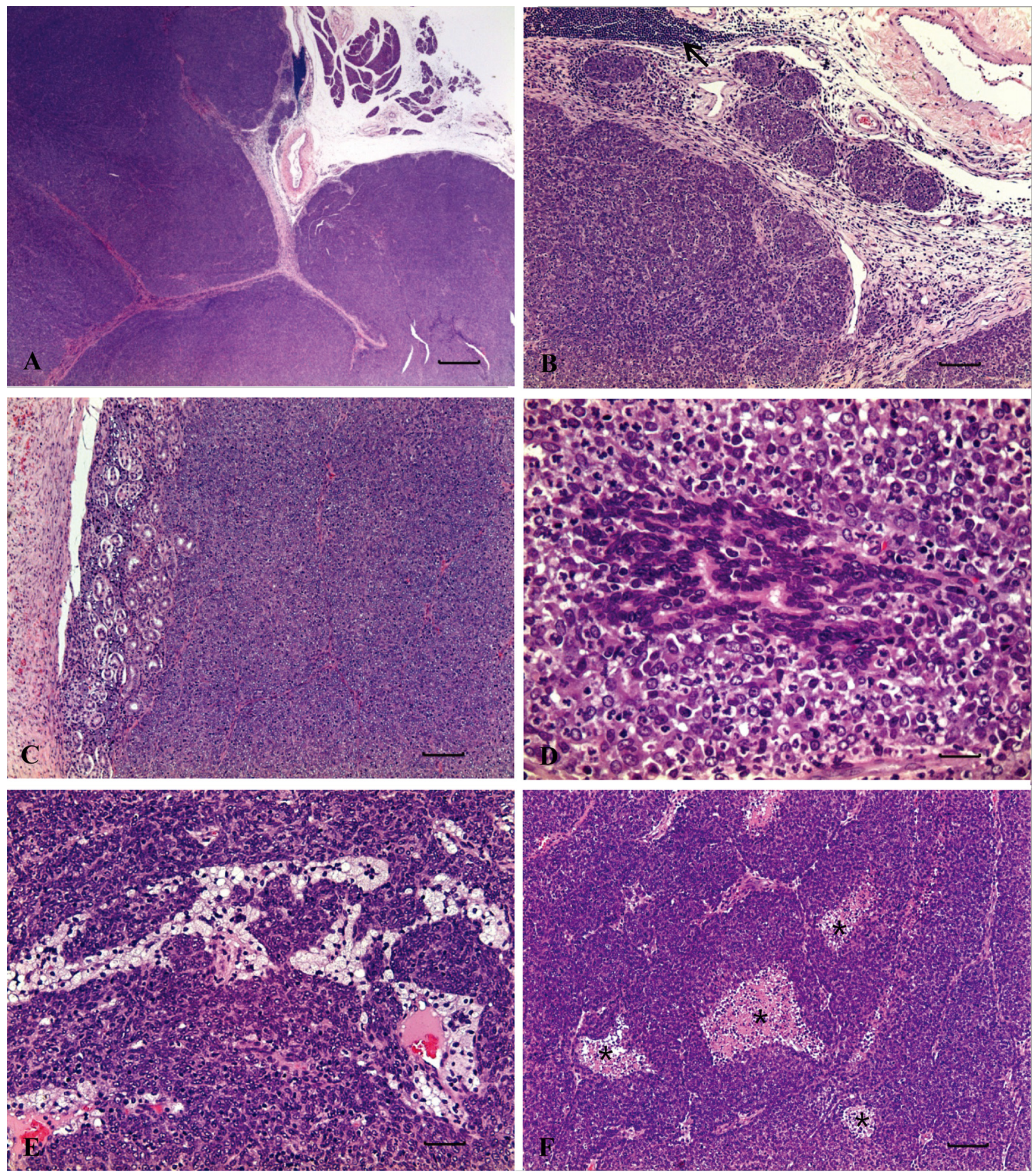

Fig. 2. H\&E staining of the tumor and normal part of the salivary glands. A: The tumor is lobulated, with the lobules separated by thin connective tissue, and the tumor compressed the surrounding tissue. The parotid gland can be seen in the upper right corner. Scale bar $=500$ $\mu \mathrm{m}$. B: Nests of tumor cells are seen outside the capsule. Lymphocytic infiltration is recognized in the thin connective tissue (arrow). Scale bar $=100 \mu \mathrm{m}$. C: On the left, the fibrous capsule surrounds the residual submandibular gland and tumor. In the middle, the normal part of the submandibular gland is adjacent to the tumor. The tumor consisted of a diffuse solid growth of small ovoid to spindle-shaped cells. Scale bar $=100 \mu \mathrm{m}$. D: Small duct-like structures lined with a monolayer of cuboidal epithelial cells. Cell debris and infiltration of neutrophils are observed. Scale bar $=25 \mu \mathrm{m}$. E: Large polygonal clear cells are observed in some areas. Scale bar $=50 \mu \mathrm{m}$. F: Necrotic foci are observed in solid growth areas (asterisks). Scale bar $=100 \mu \mathrm{m}$. 
On the basis of the histological appearance, the tumor diagnosis was consistent with EMC, which was further confirmed by the IHC investigation. An EMC is an extremely rare tumor, and only a few cases of EMC have been reported in the human salivary gland ${ }^{12,13}$. However, the term EMC has not been used for the classification of salivary gland tu- mors in rodents.

Histogenetic classification is hampered by the difficulty in determining the origin of a specific cell type in salivary gland tumors. Because the identification of myoepithelial cells, which constitute the basal layer of normal salivary gland epithelia, may be difficult in routinely stained sections,

Table 2. Results of IHC Staining for Comparison Between the Tumor and the Normal Part of the Salivary Gland

\begin{tabular}{|c|c|c|c|c|c|}
\hline \multirow[b]{2}{*}{ Markers } & \multicolumn{3}{|c|}{ Cell component of tumor } & \multicolumn{2}{|c|}{ Cell type of intercalated duct } \\
\hline & Epithelial & Myoepithelial & Ovoid or spindle cells & Epithelial & Myoepithelial \\
\hline CK AE1/AE3 & ++ & - & ++ & ++ & - \\
\hline EMA & ++ & - & ++ & ++ & - \\
\hline aSMA & - & + & + & - & ++ \\
\hline Vimentin & - & ++ & + & - & ++ \\
\hline p63 & - & ++ & ++ & - & + \\
\hline Calponin & - & + & + & - & ++ \\
\hline Calcitonin & - & - & - & - & - \\
\hline Synaptophysin & - & - & - & - & - \\
\hline Chromogranin A & - & - & - & - & - \\
\hline
\end{tabular}

CK AE1/AE3, cytokeratin AE1/AE3; EMA, epithelial membrane antigen; $\alpha$ SMA, $\alpha$-smooth muscle actin. -, negative; +, positive for a limited number of cells; ++, intensely positive for numerous cells.
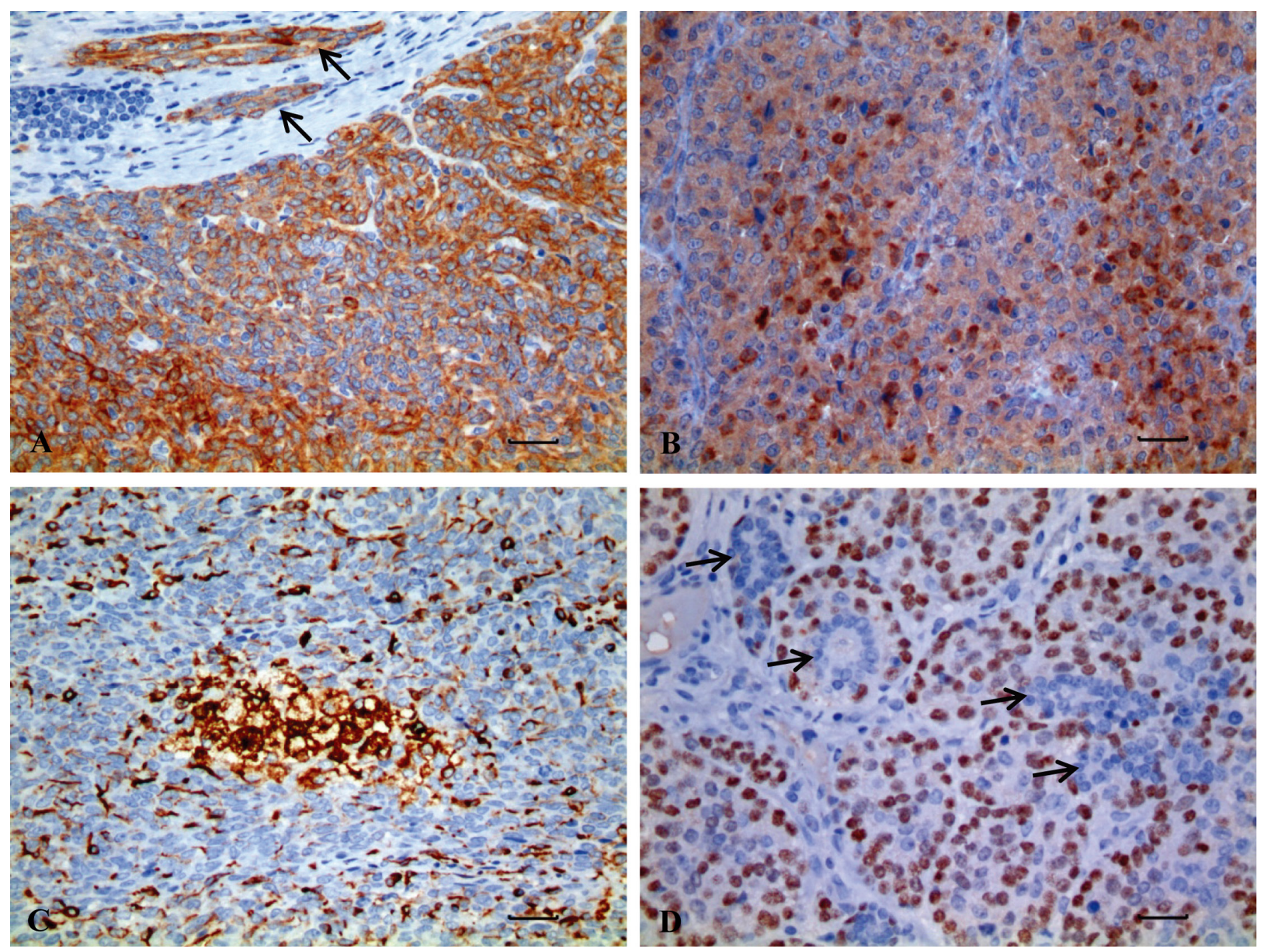

Fig. 3. IHC staining of the tumor and normal part of the submandibular gland. A: The tumor and duct epithelial cells in the normal part (arrows) show diffuse positive membraneous and cytoplasmic staining for CK AE1/AE3. Scale bar $=25 \mu \mathrm{m}$. B: The tumor cells show diffuse positive cytoplasmic staining for EMA. Scale bar $=25 \mu \mathrm{m}$. C: The tumor cells show positive cytoplasmic staining for vimentin. Scale $b a r=25 \mu \mathrm{m}$. D: The tumor cells show positive nuclei staining for p63 but no p63 positivity in ductlike structures (arrows). Scale bar $=25 \mu \mathrm{m}$. 
several IHC markers have been used to demonstrate the presence of epithelial cells and myoepithelial cells in order to determine their role in the histogenesis of salivary gland tumors. Diagnosis by IHC analysis involves various criteria, and studies have commonly reported positivity for epithelial markers including cytokeratin and $\mathrm{EMA}^{15}$. Calponin and $\alpha$ SMA have also been reported to be sensitive markers of myoepithelial differentiation in salivary glands ${ }^{16,17}$. Therefore, to ensure sensitivity of detection, a panel of specific epithelial markers (CK AE1/AE3 and EMA), specific myoepithelial markers (calponin and $\alpha$ SMA) and nonspecific myoepithelial markers (vimentin and p63) were used in this study $^{18}$. In the present tumor, CK AE1/AE3 and EMA were expressed in the epithelial component, whereas vimentin, calponin, $\alpha$ SMA and p63 were expressed in the myoepithelial component. The morphological and IHC characteristics of the epithelial and myoepithelial components in the present case were identical to those of the intercalated duct epithelial cells and myoepithelial cells in the normal part of the submandibular gland, respectively (Table 2). In addition, the histological features of this tumor were similar to those of EMC of the salivary gland in humans ${ }^{12,13}$. Therefore, these characteristics strongly suggest that the tumor originated from both the luminal epithelial and myoepithelial cells of the intercalated duct in the submandibular gland. Furthermore, the oval or spindle-shaped tumor cells were positive for epithelial and myoepithelial markers (Table 2), suggesting that these tumor cells had differentiated into epithelial and myoepithelial cells. Therefore, the characteristic of tumor cell differentiation was correlated with the high-grade malignant nature in the present tumor.

For differential diagnosis, mammary gland tumor, thyroid gland tumor and neuroendocrine origin tumor, all of which occur in a similar anatomical location, were considered. Mammary gland tumors mainly consist of glandular (ducts, ductules or alveoli) and fibrous connective components. In the present case, there were no histological findings suggestive of mammary gland tumors. A tumor of thyroid gland origin would be positive for calcitonin, a specific thyroid tissue marker, and a tumor of neuroendocrine origin would be positive for specific neuroendocrine tissue markers such as synaptophysin or chromogranin $\mathrm{A}^{19,20}$. However, the tumor cells in our case were negative for calcitonin, synaptophysin and chromogranin A.

Furthermore, the differential diagnosis could include other salivary gland tumors such as pleomorphic adenoma, adenoid cystic carcinoma and basal cell adenoma/carcinoma. Because this tumor did not show a clear mucoid stromal component (found in pleomorphic adenomas), a cribriform pattern (found in adenoid cystic carcinomas) or a distinct basement membrane-like structure and a characteristic nuclear palisading appearance at the periphery (found in basal cell adenoma/carcinomas), it could not be classified as any of the above salivary gland tumor types.

In the salivary gland, criteria that have been reported to be helpful in differentiating between benign and malignant tumors include cytological atypia, mitotic activity and tu- mor infiltration into the surrounding salivary gland or other normal tissues ${ }^{14}$. In this case, rapid tumor growth, a fishflesh sarcomatoid gross appearance, a diffuse solid growth pattern, the lack of any clear acinar structure or little tubular structure, prominent mitotic figures, necrotic foci and a tumor infiltrative margin, features associated with malignant behavior, were microscopically observed.

In conclusion, on the basis of morphological and IHC characteristics, the tumor was diagnosed as a rare spontaneous EMC in the submandibular gland. To the best of the authors' knowledge, there are very few reports on spontaneous epithelial tumors of the salivary gland, especially EMC. Given the nature of EMC, which has biphasic features with a variable combination and concentration of each components and a wide range of variations in histomorphology, more research to compile and further characterize EMC in rats is warranted. We hope that this data will aid in the classification of this uncommon tumor in rats in the future.

Acknowledgments: The authors would like to thank Mr. Kim (Hyun Yong Kim), a technician at the Department of Pathology of Kyungpook National University Medical Center, for technical assistance. We would like to thank Editage for providing editorial assistance.

\section{References}

1. Iwata H, Hirouchi Y, Koike Y, Yamakawa S, Kobayashi K, Yamamoto T, Kobayashi K, Inoue H, and Enomoto M. Historical control data of nonneoplastic and neoplastic lesions in F344/DuCrj Rat. J Toxicol Pathol. 4: 1-24. 1991. [CrossRef]

2. Elwell MR, and Leininger JR. Tumours of the salivary and lacrimal glands. In: Pathology of Tumours in Laboratory Animals. VS Turusov, and U Mohr (eds). IARC Scientific Publications, Lyon, France. 1: 89-107. 1990.

3. Neuenschwander SB, and Elewell WR. Salivary glands. In: Pathology of the Fischer Rat Reference and Atlas. GA Booman, SL Eustis, MR Elurll, CA Montgomery Jr, and WF Mackenzie (eds). Academic Press, New York. 31-42. 1990.

4. Sasaki S. A primary neoplasm in the submaxillary gland of a rat. J Comp Pathol. 92: 437-443. 1982. [Medline] [CrossRef]

5. Kobayashi Y, Eda H, Kajino E, Tate Y, Hiruma M, Akie Y, Saito A, and Kadota T. Spontaneous basal cell carcinoma of the submandibular gland in a rat. J Toxicol Pathol. 23: 147-149. 2010. [Medline] [CrossRef]

6. Halter SA, Wetherall N, and Holscher M. Adenocarcinoma of the parotid gland in nude rats. Lab Anim Sci. 33: 287289. 1983. [Medline]

7. Okada M, Seto T, Tsukidate K, Chiba T, Sobue M, and Takeuchi J. A cell line from pleomorphic adenoma of rat salivary gland. Jikken Dobutsu. 34: 67-71. 1985. [Medline]

8. Tsunenari I, Yamate J, and Sakuma S. Poorly differentiated carcinoma of the parotid gland in a six-week-old SpragueDawley rat. Toxicol Pathol. 25: 225-228. 1997. [Medline] [CrossRef]

9. Nishikawa S, Sano F, Takagi K, Okada M, Sugimoto J, 
and Takagi S. Spontaneous poorly differentiated carcinoma with cells positive for vimentin in a salivary gland of a young rat. Toxicol Pathol. 38: 315-318. 2010. [Medline] [CrossRef]

10. Hosokawa $\mathrm{S}$, Imai $\mathrm{T}$, Hayakawa $\mathrm{K}$, Fukuta $\mathrm{T}$, and Sagami F. Parotid gland papillary cystadenocarcinoma in a Fischer 344 rat. Contemp Top Lab Anim Sci. 39: 31-33. 2000. [Medline]

11. Seifert G, and Sobin LH. The World Health Organization's histological classification of salivary gland tumors. A commentary on the second edition. Cancer. 70: 379-385. 1992.

12. Angiero F, Sozzi D, Seramondi R, and Valente MG. Epithelial-myoepithelial carcinoma of the minor salivary glands: immunohistochemical and morphological features. Anticancer Res. 29: 4703-4709. 2009. [Medline]

13. Ramraje SN, Bharambe BM, and Zode R. Epithelial myoepithelial carcinoma of the submandibular salivary gland. Bombay Hosp J. 52: 141-143. 2010.

14. Ozaki K, and Narama I. Pleomorphic adenoma of the salivary gland in two prairie dogs (Cynomys ludovicianus). J Toxicol Pathol. 16: 171-173. 2003. [CrossRef]

15. Cosentino TB, Brazão-Silva MT, do Nascimento Souza KC, de Faria PR, de Moraes S, Loyola AM, da Silva SJ, Cardoso SV. Myoepithelial carcinoma of the submandibular gland: report of a case with multiple cutaneous metastases. Oral Surg Oral Med Oral Pathol Oral Radiol Endod. 106: 26-29. 2008.

16. Furuse C, Sousa SO, Nunes FD, Magalhães MH, and Araújo VC. Myoepithelial cell markers in salivary gland neoplasms. Int J Surg Pathol. 13: 57-65. 2005. [Medline] [CrossRef]

17. Jones H, Moshtael F, and Simpson RH. Immunoreactivity of alpha smooth muscle actin in salivary gland tumours: a comparison with S100 protein. J Clin Pathol. 45: 938-940. 1992. [Medline] [CrossRef]

18. Gama A, Alves A, Grater F, and Schitt F. p63: A novel myoepithelial cell marker in canine mammary tissue. Vet Pathol. 40: 412-420. 2003. [Medline] [CrossRef]

19. Martín-Lacave I, Rojas F, Bernabé R, Utrilla JC, Fernández-Santos JM, De Miguel M, and Conde E. Comparative immunohistochemical study of normal, hyperplastic and neoplastic $\mathrm{C}$ cells of the rat thyroid gland. Cell Tissue Res. 309: 361-368. 2002. [Medline] [CrossRef]

20. Paltrinieri S, Riccaboni P, Rondena M, and Giudice C. Pathologic and immunohistochemical findings in a feline aortic body tumor. Vet Pathol. 41: 195-198. 2004. [Medline] [CrossRef] 